\title{
Erratum to: Surface-Enhanced Raman Plasmon in Self-Assembled Sulfide-Coated Gold Nanoparticle Arrays
}

\author{
Adilson R. Prado ${ }^{1,2}$ - Jairo P. Oliveira ${ }^{3}$. Rayssa H. A. Pereira ${ }^{3}$. \\ Marco C. C. Guimarães ${ }^{3}$ Breno V. Nogueira ${ }^{3}$ - Eustáquio. V. R. Castro ${ }^{4}$. \\ Luiz. C. P. Almeida ${ }^{4,5}$ - Moisés R. N. Ribeiro ${ }^{2}$ - Maria J. Pontes ${ }^{2}$
}

Published online: 24 April 2015

(C) Springer Science+Business Media New York 2015

\section{Erratum to: Plasmonics}

\section{DOI 10.1007/s11468-015-9909-2}

In the original version of this paper, the captions of Figures 5 , 6 and 7 are switched. The correct form is:

Fig 5 - should be replaced by the caption of Fig. 7. It means: Caption Fig 5/correct form: Raman maps from Raman spectroscopy. 3D for gold nanoparticles a without sulfide and $\mathbf{b}$ with sulfide, both excited by $532 \mathrm{~nm}$ laser

Fig 6 - should be replaced by the caption of Fig. 5. It means: Caption Fig 6/correct form: Raman spectra of AuNP's excited by lasers emitting in 532 and $633 \mathrm{~nm}$. Raman spectra peaks are labeled on the graph

Fig 7 - should be replaced by the caption of Fig. 6. It means: Caption Fig 7/correct form: Raman spectra of gold nanoparticles with citrate and sulfide excited by lasers emitting in $532 \mathrm{~nm}$. Raman spectra peaks are labeled on the graph, excited by $532 \mathrm{~nm}$

The online version of the original article can be found at http://dx.doi.org/ 10.1007/s11468-015-9909-2.

Adilson R. Prado

Maria J. Pontes

adilsonp@ifes.edu.br

Jairo P. Oliveira

oliveira.jp@outlook.com

Rayssa H. A. Pereira

rayssaharper@hotmail.com

Marco C. C. Guimarães

marco.cunegundes@gmail.com

Breno V. Nogueira

brenovalentim@gmail.com

Eustáquio. V. R. Castro

eustaquiovinicius@uol.com.br

Luiz. C. P. Almeida

lcpaluiz@gmail.com

Moisés R. N. Ribeiro

moises@ele.ufes.br

maria.pontes@ufes.br

Instituto Federal do Espírito Santo, km 6.5 ES 010, Serra, ES, Brazil 29173-087

2 Departamento Engenharia Elétrica-CTII, Universidade Federal do Espírito Santo, Av. Fernando Ferrari 514, Vitória, ES, Brazil 29060970

3 Departamento Morfologia, Lab. de Ultraestrutura Celular, Universidade Federal do Espírito Santo, Av. Marechal Campos1468, Vitória, ES, Brazil 29.040-090

4 Departamento Química, Univ. Federal do Espírito Santo, Av. Fernando Ferrari 514, Vitoria, ES, Brazil 29060-970

5 Instituto Federal do Espírito Santo, Rodovia 482, Cachoeiro - Alegre, $\mathrm{km}$ 47, Alegre, ES, Brazil 29500000 